\title{
Blood pressure, flow, and peripheral resistance of digital arteries in vibration syndrome
}

\author{
M FUTATSUKA, ${ }^{1}$ I PYYKKÖ,${ }^{2}$ M FÄRKKILÄ, ${ }^{3}$ O KORHONEN, ${ }^{4}$ AND J P STARCK ${ }^{4}$
}

From the Department of Public Health,' Kumamoto University Medical School, Japan, Department of Otorhinolaryngology, ${ }^{2}$ University Hospital of Lund, Sweden, Department of Neurology, ${ }^{3}$ University Hospital of Helsinki, and Institute of Occupational Health, ${ }^{4}$ Helsinki, Finland

ABSTRACT The peripheral circulation was studied in 19 lumberjacks and in 12 control subjects. Twelve of the lumberjacks were free from vascular symptoms and seven had vibration induced white finger (VWF). Using the strain-gauge plethysmographic technique, the digital circulation was examined at rest, during cooling of the upper body, and during heating of the upper body. At rest and during vasodilatation no significant differences were found between the lumberjacks and the controls. During reflexive vasoconstriction, digital blood flow in the upper body was more reduced in lumberjacks with VWF than in control subjects. Furthermore, digital blood pressure of the lumberjacks with VWF fell more than in the control group. The peripheral resistance also increased more, but this difference was not statistically significant. There was no evidence that the exaggerated vasoconstriction of VWF resulted from a narrowing of the lumen of arterioles due to hypertrophy of the vessel wall. The present findings suggest that VWF is produced by the highly sensitive responsiveness of the affected vessel to normal vasoconstrictor stimuli.

The vibration syndrome is comprised of disorders of the circulation, the peripheral nerves, the muscles, and the bones and joints, each of which may occur separately or together. ${ }^{2}$ The vascular symptoms of vibration syndrome resemble the spontaneous vasoconstrictive disease first described by Raynaud ${ }^{3}$ in which paroxysmal ischaemia in the finger or the hands is provoked by cold weather. The vasoconstriction of the blood vessels in the fingers usually lasts from five to 30 minutes, during which time the fingers are white and pale. ${ }^{4-6}$ Recovery is achieved by massaging or by the local application of warmth. These vasoconstrictions seldom lead to malnutrition or to atrophy of the skin, though a few such cases have been reported. ${ }^{178}$ This symptom has a wide variety of names, including Raynaud's phenomenon of occupational origin, ${ }^{9}$ white fingers, ${ }^{10}$ dead fingers, ${ }^{11}$ traumatic vasospastic disease, ${ }^{51213}$ and, more recently, vibration induced white finger (VWF). ${ }^{14}$

An increase in the output of the sympathetic nervous system regulating the digital vessels has generally been considered the aetiology of primary Raynaud's phenomenon. By analogy, subjects with

Received 9 August 1982

Accepted 8 November 1982
VWF react to different sympathetic stimuli with stronger vasoconstriction than control subjects, ${ }^{515-17}$ and this has been regarded as a defect in the centre controlling vasomotor tone. ${ }^{18} 19$ There is still no evidence, however, that the sympathetic nervous tone is raised in subjects with VWF. Allegedly, the activation of sympathetic nervous tone contributes to an attack of VWF, but, as recently pointed out, ${ }^{2021}$ a cold stimulus locally applied to the fingers combined with temporary ischaemia can also provoke an attack of VWF.

Animal experiments conducted in spontaneously hypertensive rats indicate that vibration powerfully stimulates the sympathetic nervous system and triggers hypertension. ${ }^{22}$ As a result of exposure to vibration, the resistance of the arterioles and the arteriovenous shunts increases because of hypertrophy in the muscular layer of the vessel wall. ${ }^{23}$ The affected vessels subsequently react with stronger constriction even to the normal amount of impulses from the sympathetic vasoconstrictor nerve. Muscular hypertrophy in the arterioles has been reported among subjects with $\mathrm{VWF}^{24}$ causing the vessels to reach the point of critical closing pressure more quickly, ${ }^{25}$ thus setting off an attack of VWF. ${ }^{15}$ Azuma et al, however, have recently shown that vibration sensitises the smooth muscle to noradrenalin. ${ }^{2627}$ Thus, in line with the theory of Lewis, ${ }^{28}$ the 
cause of VWF is the exaggerated constriction of the vessel wall to a normal amount of vasoconstrictor nerve output; during exposure to cold, this would precipitate an attack of VWF.

In the present study the plethysmographic technique was used to study the circulation of blood in the fingers and arms of lumberjacks suffering from VWF. The same techniques were used to study healthy controls and lumberjacks without VWF, and the results from all the groups were compared. The objectives were: (1) to determine whether the haemodynamic mechanisms of the subjects with VWF when reflexively induced differed from the haemodynamic mechanisms of the other groups and (2) to clarify whether the cause of VWF was either excessive contractibility of the digital vessels or an increase in the muscular layer encroaching on the lumen of the vessels.

\section{Subjects and methods}

The study was carried out in connection with the professional lumberjacks' annual medical examination, which occurred in northeastern Finland in early May 1981. All subjects in the parish of Suomussalmi who worked for the National Board of Forestry were examined. A detailed description of the subjects examined has been published in connection with earlier studies. ${ }^{529} 30$

The subjects for this part of the study were selected to fit into one of the following groups:

(A) healthy control subjects without exposure to vibration,

(B) subjects occupationally exposed to hand-arm vibration but without VWF, and

(C) subjects occupationally exposed to hand-arm vibration and with VWF.

Of the 30 or so men coming each day, we were only able to study about six men daily for this investigation. They were randomly selected from the men fulfilling the criteria given above. Altogether, 31 men were studied. Table 1 shows the subjects' mean age, range, and periods of operating chain saw.

MEASUREMENT OF THE CIRCULATION

A detailed history of hand-arm symptoms and other relevant medical disorders and the duration of exposure to vibration were recorded. A routine medical examination was carried out. ${ }^{5}$ Only subjects with no disorder predisposing to circulatory disturbances other than vibration exposure were included. in the study. A cold provocation test was done for each subject with a history of VWF.

The investigation of the circulation comprised the measurement of systolic blood pressure in the upper arm, the digital systolic blood pressure, and the digital blood flow from the finger in which the Raynaud's phenomenon occurred most frequently. The same measurements for subjects without VWF were taken from the third finger. Skin temperature was measured at the inner elbow and at the tip of either the most affected or the third finger. During the measurements the subject was lying supine and kept his hands at heart level.

The blood pressure in the upper arm was measured by the auscultatory technique. A $12 \times 28$ cuff was wrapped around the upper arm, and the systolic blood pressure was recorded as the point at which the first tone was audible. To measure the digital systolic blood pressure, a $1 \times 5$ cuff was placed around the proximal phalange. A mercury-inrubber strain-gauge was placed around the distal phalanx of the same finger. The pulse wave detected by the strain-gauge was recorded on paper (Medimatic Strain Gauge Plethysmograph SP2, Denmark). In the practical measurements of the digital systolic blood pressure the cuff was fully inflated around the distal phalanx of the finger, whereafter it was deflated at a constant rate. The digital systolic blood pressure was recorded on the curve as a point where an increased volume was observed (fig 1).

The arterial blood flow was calculated as described by other authors using this technique using the slope of the curve which displayed the decrease in volume with time (fig 1). ${ }^{31-34}$ For calibration, an electrical signal was used that indicated a $1 \%$ increase in volume of the measured limb-segment equalling $1 \mathrm{ml} / 100 \mathrm{ml}$ blood flow. The measurements were taken three times, and their arithmetical mean was used for each measurement.

The peripheral resistance of the finger circulation

Table 1 Age and sawing time in the study groups

\begin{tabular}{lccc}
\hline Group & No & Age (years) & Sawing time (hours) \\
\hline (A) Healthy & 12 & $41 \cdot 3 \pm 8.9$ & $191 \pm 296$ \\
(Without exposure) & 12 & $(25-54)$ & $(0-810)$ \\
(B) Healthy & $40.6 \pm 8.4$ & $15883 \pm 6176$ \\
(With exposure) & 7 & $(24-54)$ & $(4815-26075)$ \\
(C) Affected & & $41.6 \pm 7 \cdot 5$ & $12365 \pm 5890$ \\
& $(27-50)$ & $(4600-18838)$ \\
\hline
\end{tabular}

$M \pm S D$ (range) 


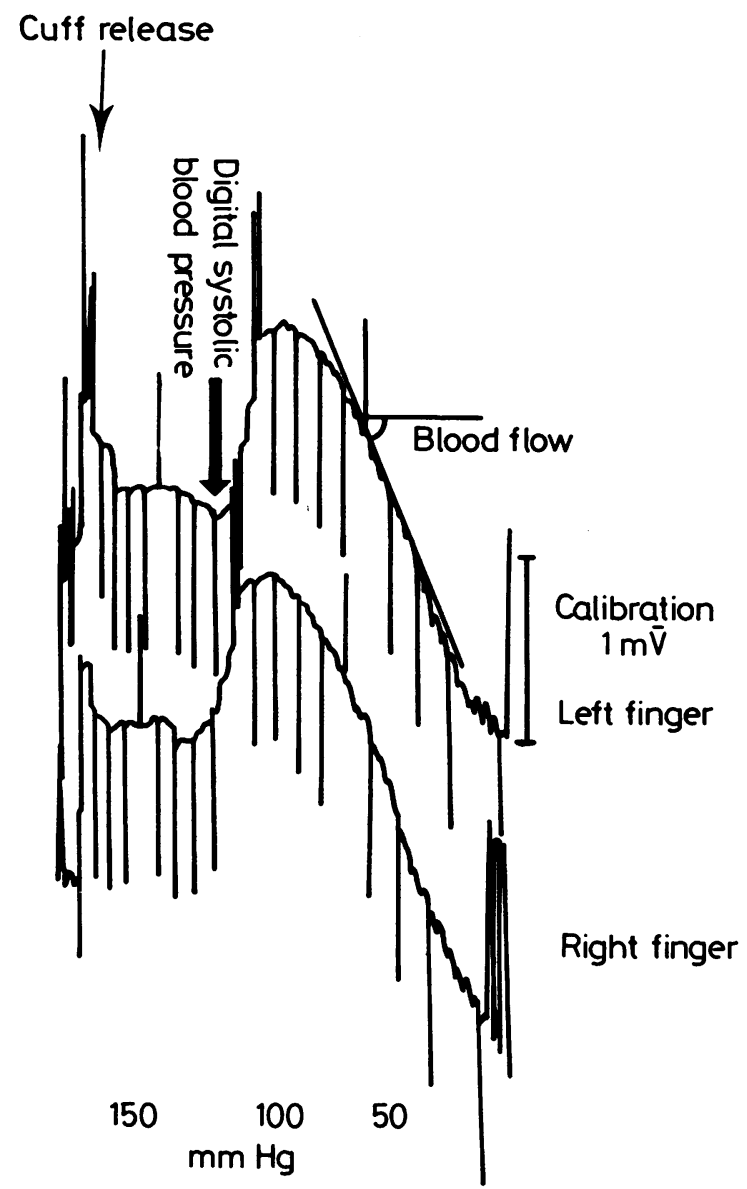

Fig 1 An example of a recording curve showing parameters determined for each measurement.

was estimated using the following formula. ${ }^{35} 36$

$$
\mathbf{R}_{\text {local }}=\frac{\mathbf{P}_{\text {local }}}{\mathrm{Q}}
$$

where Rlocal is the peripheral resistance of digital circulation, Plocal is the digital blood pressure, and $\mathrm{Q}$ is the digital blood flow.

The peripheral total resistance of hand-arm circulation was calculated as follows:

$$
\mathbf{R}_{\text {coll }}=\frac{\mathbf{P}_{\text {system }}-\text { Plocal }_{\text {lol }}}{\mathbf{Q}}
$$

where $R_{\text {coll }}$ is the total resistance of the hand-arm circulation and Psystem is the blood pressure of the upper arm.

The parameters were calculated during three conditions: at rest; at vasoconstriction; and at vasodilatation.

\section{RESTING VASCULAR TONE}

The subjects were prohibited from smoking during the day of examination and from drinking alcohol the day before investigation. The subjects were lying supine for 15 minutes in room temperature of $20-$ $24^{\circ} \mathrm{C}$. The fingers were kept at mid-axillary level at rest. Normal indoor clothing was worn during the measurements.

\section{INCREASED VASCULAR TONE}

Cooling of the body was performed by adjusting the room temperature to $10-15^{\circ} \mathrm{C}$ and by placing blankets perfused with water at $2-4^{\circ} \mathrm{C}$ on the bare chest of the subjects for 15 minutes. The measurements were then taken.

\section{REDUCED VASCULAR TONE}

Vasodilatation was induced by passively warming the subjects and by the administration of $27 \mathrm{~g}$ of ethyl alcohol by mouth. Passive warming was achieved by putting the subjects for 30 minutes into a room where the ambient temperature was 36$40^{\circ} \mathrm{C}$, whereafter the measurements were taken.

\section{STATISTICAL EVALUATION}

The mean and standard deviation and the standard error of the mean were calculated for each variable and for each group. The data were compared between the different groups using Student's $t$ test for unpaired data. Regression analysis was used to compare the data reflecting the relationship between peripheral resistance and blood flow. The curves were analysed by fitting individual points to an exponential curve $y=a b^{x}$. The data were converted to a linear form: $\log y=\log a+\log b$. The following parameters were computed: the intercept (a) and the slope (b) for the equation; the correlation coefficient (r); and the estimate of the standard error. Statements of statistical significance were based on a probability level of $5 \%$.

\section{Results}

At room temperature the controls and the lumberjacks with or without VWF showed no significant differences in the mean systolic arterial pressure of the upper arm or the affected finger, in digital blood flow, or in peripheral resistance of the fingers (table 2).

After the upper body was cooled the skin temperature of the fingers and at the elbow decreased, on average, $8^{\circ} \mathrm{C}$ and $5^{\circ} \mathrm{C}$ respectively in all groups (table 3). The lumberjacks with VWF tended to react to cold with lower skin temperatures and higher digital systolic pressure, but the differences were not statistically significant. A significant 
Table 2 Skin temperature, blood pressure, blood flow, and resistance in control subjects (A), lumberjacks without VWF $(B)$, and lumberjacks with $V W F(C)$ when at rest. Means and standard deviations are given

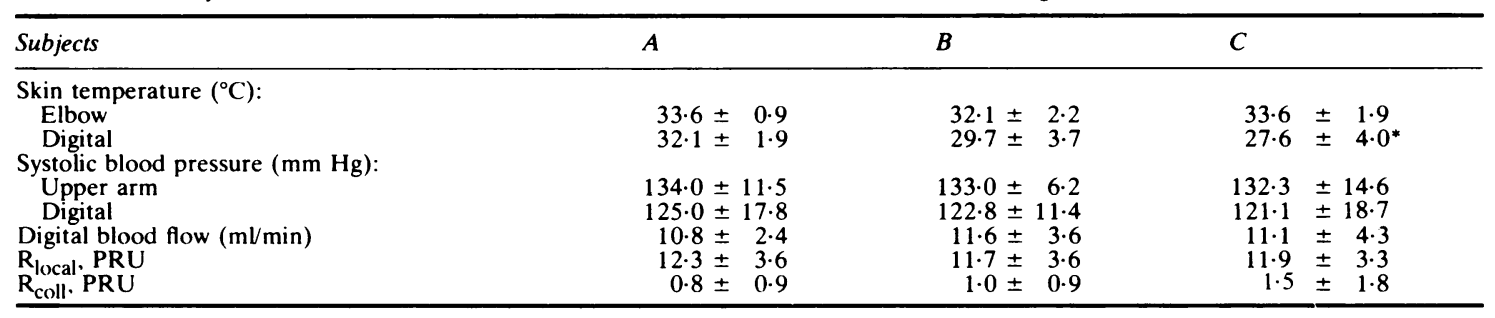

${ }^{*} p<0 \cdot 05$.

Table 3 Skin temperature, blood pressure, blood flow, and resistance in control subjects (A), lumberjacks without VWF $(B)$, and lumberjacks with $V W F(C)$ during reflexively induced vasoconstriction. Means and standard deviation are given

\begin{tabular}{|c|c|c|c|}
\hline Subjects & $\boldsymbol{A}$ & $B$ & $C$ \\
\hline \multicolumn{4}{|l|}{ Skin temperature $\left({ }^{\circ} \mathrm{C}\right)$ : } \\
\hline Elbow & $28 \cdot 1 \pm 1 \cdot 5$ & $27 \cdot 3 \pm 2 \cdot 0$ & $26 \cdot 5 \pm$ \\
\hline Digital & $22 \cdot 6 \pm 3 \cdot 2$ & $23 \cdot 1 \pm 2 \cdot 7$ & $20.4 \pm 2.4$ \\
\hline \multicolumn{4}{|c|}{ Systolic blood pressure $(\mathrm{mm} \mathrm{Hg})$ : } \\
\hline Upper arm & $135 \cdot 2 \pm 10 \cdot 1$ & $132.8 \pm 7.4$ & $134 \cdot 6 \pm 21 \cdot 5$ \\
\hline Digital & $125 \cdot 0 \pm 8 \cdot 0$ & $119.6 \pm 12.5$ & $115 \cdot 6 \pm 14 \cdot 0$ \\
\hline Digital blood flow ( $\mathrm{ml} / \mathrm{min})$ & $3.7 \pm 3.5$ & $5.2 \pm 2.7$ & $1.5 \pm 1.8^{*}$ \\
\hline $\mathrm{R}_{\text {local }}, \mathrm{PRU}$ & $32 \cdot 6 \pm 21.6$ & $20 \cdot 8 \pm 10 \cdot 1$ & $38 \cdot 3 \pm 14 \cdot 5$ \\
\hline $\mathrm{R}_{\text {coll. }}$ PRU & $3 \cdot 5 \pm 4 \cdot 9$ & $4 \cdot 2 \pm 6 \cdot 3$ & $7 \cdot 3 \pm 6 \cdot 2^{*}$ \\
\hline
\end{tabular}

${ }^{*} \mathrm{p}<0 \cdot(05$.

Table 4 Skin temperature, blood pressure, blood flow, and resistance in control subjects (A), lumberjacks without VWF $(B)$, and lumberjacks with $V W F(C)$ during reflexively induced vasodilatation. Means and standard deviations are given

\begin{tabular}{|c|c|c|c|}
\hline Subjects & $A$ & $B$ & $C$ \\
\hline \multicolumn{4}{|l|}{ Skin temperature $\left({ }^{\circ} \mathrm{C}\right)$ : } \\
\hline Elbow & $33.3 \pm 0.9$ & $32 \cdot 6 \pm$ & $32 \cdot 4 \pm$ \\
\hline \multicolumn{4}{|c|}{ Systolic blood pressure $(\mathrm{mm} \mathrm{Hg})$ : } \\
\hline Upper arm & $136 \cdot 2 \pm 17 \cdot 7$ & $133.5 \pm 5.5$ & $134.9 \pm 21 \cdot 1$ \\
\hline Digital & $125 \cdot 8 \pm 21 \cdot 8$ & $127 \cdot 2 \pm 10 \cdot 8$ & $127 \cdot 9 \pm 25 \cdot 5$ \\
\hline Digital blood flow $(\mathrm{ml} / \mathrm{min})$ & $11.1 \pm 3.0$ & $11 \cdot 2 \pm 3 \cdot 0$ & $11 \cdot 2 \pm 3.8$ \\
\hline$R_{\text {coll }}$. PRU & $1.0 \pm 0.9$ & $0.8 \pm 1.0$ & $0.9 \pm$ \\
\hline
\end{tabular}

decrease in the digital blood flow was found for the lumberjacks with VWF when compared with the other groups. The decrease was accompanied by increased peripheral resistance in the finger and lower arm circulation. No changes were observed in the systolic blood pressure of the upper arm.

In all groups the digital skin temperature of the elbow increased significantly on vasodilatation, but no difference between the groups was observed (table 4). Furthermore, the mean values of the systolic blood pressures of the upper arm and the fingers, the digital blood flow, and the peripheral resistance were about the same in the three groups.

The vascular tone at rest was used as a reference to which the changes detected in circulation after cooling and vasodilatation were related. A comparison of the circulatory changes between the control subjects and the lumberjacks with VWF (table 5) showed statistically significant differences in the digital blood flow and in the peripheral resistance after cooling. The responses in the lumberjacks with VWF were exaggerated. After vasodilatation no differences were found between the two groups.

To study whether the tendency to increased digital vasoconstriction among the lumberjacks with VWF found after the upper body was cooled depended on structural changes in the vessel wall, the peripheral resistance of the digital circulation was related to the digital blood flow of the control subjects and of the lumberjacks with and without 
Table 5 Changes in digital blood flow and resistance in control subjects $(A)$ and lumberjacks with $V W F(C)$ after reflexively induced vasoconstriction and vasodilatation when related to baseline values. Means and standard deviations are given

\begin{tabular}{|c|c|c|c|c|c|}
\hline \multirow[b]{2}{*}{ Subject } & \multirow[t]{2}{*}{ After cooling } & \multicolumn{2}{|l|}{ Vasodilatation } & \multirow[b]{2}{*}{$A$} & \multirow[b]{2}{*}{$C$} \\
\hline & & $A$ & $C$ & & \\
\hline $\begin{array}{l}\text { Digital blood flow } \\
\mathbf{R}_{\text {local }} \\
\mathbf{R}_{\text {coll }}\end{array}$ & $\begin{array}{l}\text { Upper arm } \\
\text { cooling/rest } \\
\text { Digital cooling/rest } \\
\text { Cooling/rest } \\
\text { Cooling/rest } \\
\text { Cooling/rest }\end{array}$ & $\begin{array}{l}1.00 \pm 0.06 \\
0.99 \pm 0.12 \\
0.56 \pm 0.23 \\
2.14 \pm 0.23 \\
0.23 \pm 0.49\end{array}$ & $\begin{array}{l}0.98 \pm 0.10 \\
0.96 \pm 0.08 \\
0.33 \pm 0.10^{* *} \\
3.28 \pm 1.25^{*} \\
0.53 \pm 0.56\end{array}$ & $\begin{array}{l}0.99 \pm 0.02 \\
1.01 \pm 0.14 \\
1.08 \pm 0.38 \\
1.51 \pm 2.09 \\
0.03 \pm 0.30\end{array}$ & $\begin{array}{r}0.98 \pm 0.07 \\
1.06 \pm 0.13 \\
1.10 \pm 0.42 \\
1.09 \pm 0.43 \\
-0.08 \pm 0.21\end{array}$ \\
\hline
\end{tabular}

${ }^{*} \mathrm{p}<0.05 ;{ }^{* *} \mathrm{p}<0.01$.
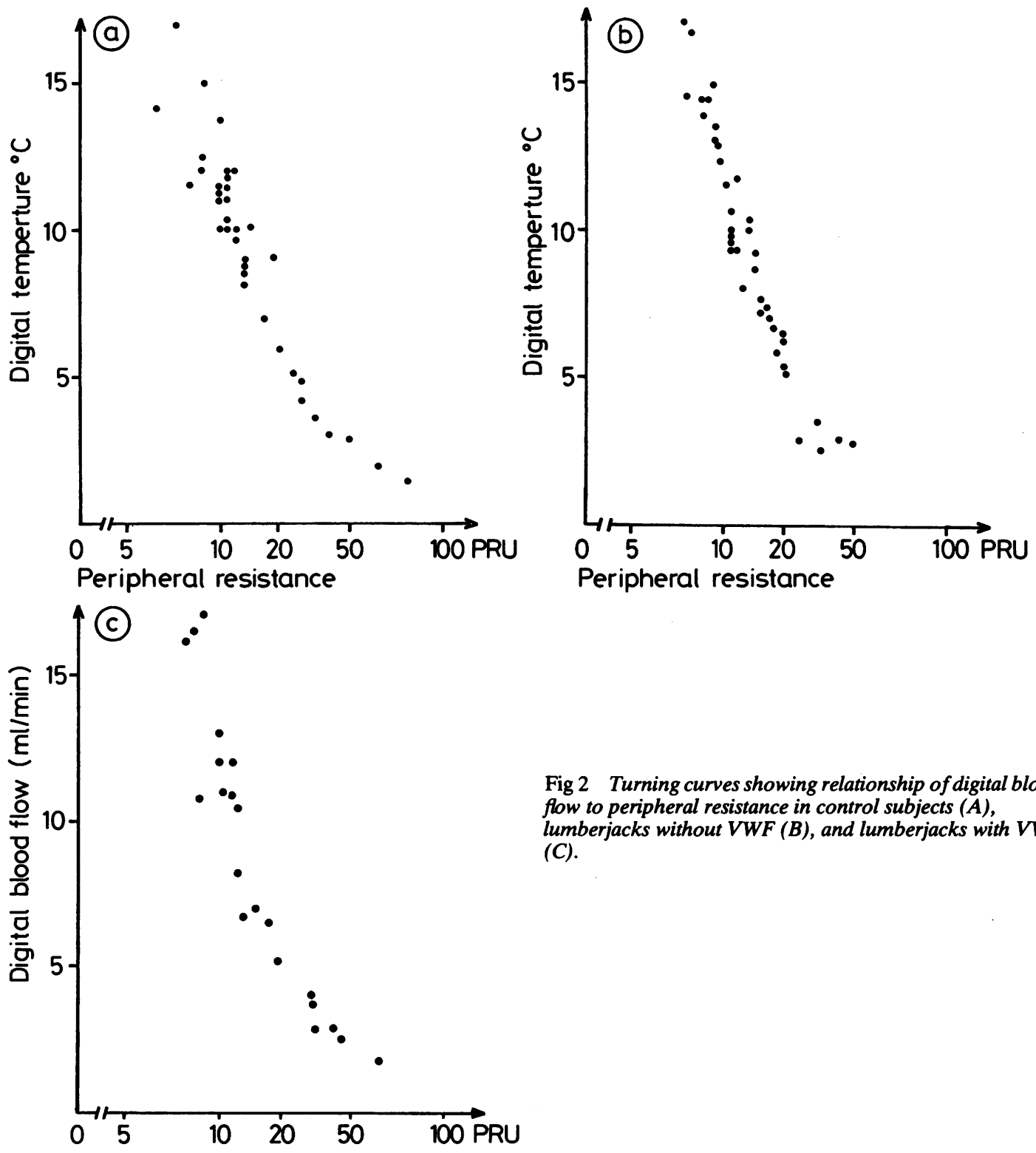

Fig 2 Turning curves showing relationship of digital blood flow to peripheral resistance in control subjects $(A)$, lumberjacks without VWF (B), and lumberjacks with VWF (C).

Peripheral resistance 
Table 6 Parameters of curves shown in fig 2 fit after logarithmic conversion for measuring points.

\begin{tabular}{lrrr}
\hline Subjects & \multicolumn{1}{l}{$\boldsymbol{A}$} & \multicolumn{1}{c}{$\boldsymbol{B}$} & \multicolumn{1}{l}{$C$} \\
\hline Intercept (a) & 60.78 & 38.22 & 45.15 \\
Slope (b) & 0.86 & 0.90 & 0.89 \\
Correlation coefficient (r) & 0.94 & 0.93 & 0.90 \\
Standard error of estimation & 0.09 & 0.07 & 0.12 \\
\hline
\end{tabular}

VWF (fig 2). No differences in the "turning curves" showing flow-resistance relationship between the groups were observed. As illustrated in table 6 (where a regression analysis was performed for the data by fitting the individual points to an exponential curve) the intercept, the slope, and correlation coefficient between the two groups were about the same.

Because simultaneously occurring changes in blood pressure can compensate the changes observed in blood flow $^{37}$ the relationship between the digital blood flow and the peripheral resistance during a constant blood pressure was examined (fig 3). For the study of this relationship all the individual values at a digital systolic blood pressure of $125 \pm 5 \mathrm{~mm} \mathrm{Hg}$ were plotted. The values recorded for the subjects with VWF followed the turning curve of the symptom-free control subjects perfectly. Thus the present turning curves (figs 2 and 3 ) indicated that subjects with VWF reacted more strongly to reflexly induced cold shift along the

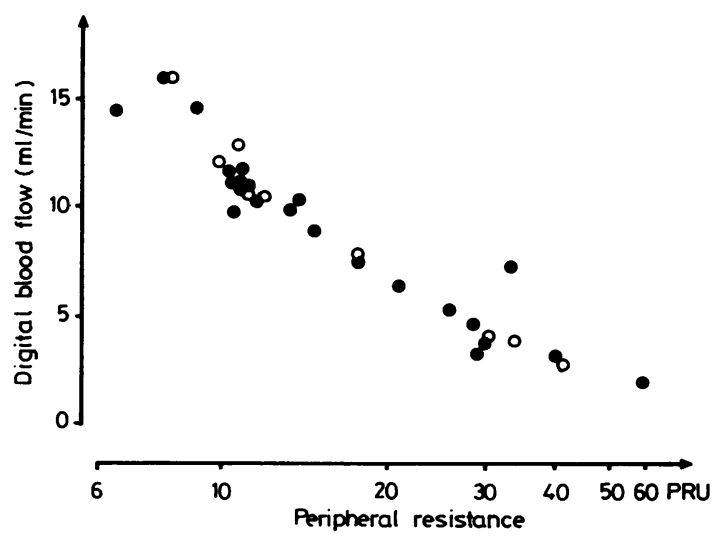

Fig 3 Digital blood flow and peripheral resistance during constant digital blood pressure in control subjects (filled circles) and in lumberjacks with VWF (open circles). normal turning curve, which turned towards the lower flow values and higher peripheral resistance values.

\section{Discussion}

Lewis was the first to hypothesise that VWF is caused by defects in the nerve endings, leading to excessive vasoconstriction when the vessel wall is exposed to cold. ${ }^{28}$ Extending this theory, Magos and Okos showed not only that the vessels reacted more strongly to locally applied cold but also that cold induced vasodilatation was lost. ${ }^{38}$ This excessive response was explained as the result of the accumulation of vasoactive substances that cannot be metabolised by the affected vessels. Challenging this theory, Hellström and Langer showed a normal degree of cold induced vasodilatation in subjects with VWF. ${ }^{39}$ Furthermore, Okada et al were not able to show an excessive amount of the metabolites of noradrenalin in the urine of subjects with VWF during cold provocation when compared with normal subjects. ${ }^{40}$

Furthermore, the hyper-reactivity of the vessels of subjects with VWF does not seem to be limited to locally applied cold stimulus. Reflexively induced cold, noise, and vibratory stimuli also cause an enhanced vasoconstriction in the affected vessels. ${ }^{51617}$ Confirming the hyper-responsiveness of the digital vessels, the lumberjacks with VWF in the present study reacted with stonger vasoconstriction to the cooling of the upper body than the control subjects. Interestingly, Azuma et al ${ }^{26}{ }^{27}$ have recently shown both in vivo and in vitro, that the smooth muscles of the vessel wall exposed to vibration respond more strongly to noradrenalin than the smooth muscles of the vessel wall not so exposed. In subjects with VWF normal vasoconstrictor nerve tone can lead to increased peripheral resistance by the strong contraction of the arterioles and arteriovenous shunts. If excessive this contraction, concomitantly with decreased blood flow, can finally lead to the collapse of the vessel wall and an attack of VWF. Nevertheless, similar vascular hyperresponsiveness to noradrenalin as shown by Azuma et $a^{2627}$ has also been observed by Folkow and coworkers $^{22} 37$ in cases where the muscular layer of the arterioles and the arteriovenous shunts was increased.

In experiments with spontaneously hypertensive rats of the Okamoto strain Folkow and coworkers showed that strain from increased blood pressure caused an increased thickness of the muscular layer. ${ }^{37}$ The increased wall thickness evidently encroached on the lumen and decreased the blood flow even when at rest, leading to a greater flow 
resistance ${ }^{37}$ This together with an unchanged sensitivity to noradrenalin caused a more steeply increased resistance and a higher maximal pressor response to larger concentrations of noradrenalin. Thus when the alpha-receptors located on the outer part of the muscular layer of the resistance vessels ${ }^{41}$ was stimulated, an enhanced response in flow resistance followed. ${ }^{37}$ When these rats were exposed to noise and vibration stimuli, the vascular changes described above were observed, on average, after three weeks of exposure. It is noteworthy that vibration proved to be a stronger stimulus in causing these changes than noise. Allegedly, an increase in wall/lumen ratio such as the increase reported by Ashe $e t a l^{24}$ could be the explanation for both the increased reactivity of the vessels observed in VWF and the increased supra-threshold responsiveness to sympathetic stimuli.

In line with these findings our results show that the peripheral resistance of the digital arteries was increased during exposure to cold. We were unable to show that this increase resulted from an increased wall/lumen ratio in the digital arteries, however. On the contrary, the results showed that at constant pressure, the blood flow-peripheral resistance curves were identical for the lumberjacks with VWF and for the subjects without VWF (figs 2 and 3 ). The increased peripheral resistance indicated that the subjects with VWF reacted with extreme vasoconstriction to reflexly induced cooling. During reflexly induced vasodilatation these subjects had a normal capacity for vasodilatation. Thus reactivity to a given stimulus was exaggerated, but the responses followed the normal flow-resistance curve.

Our results do not show whether the increased response to cold are caused by a locally increased reactivity to efferent nerve impulses or whether the number of nerve impulses is increased as compared with control subjects. According to several authors vibration is able to induce changes in the central nervous system, which controls vascular reflexes. ${ }^{517-1930}$ The recent studies of Azuma et al emphasise the importance of local factors in the vessel wall, in which a normal amount of vasoconstrictor impulses provoke increased responsiveness. ${ }^{26} 27$ Allegedly, enhanced vasoconstriction may be produced in combination with central and peripheral factors, such as the cooling of the body and the vessels of the finger. The former stimulus enhances responses of the latter stimulus.

The subjects of our study were characterised by a mild stage of VWF which was consistently functional in character. There is still some controversy as to whether the most severe stages of VWF include the development of structural changes as secondary changes. ${ }^{14}$ Similar studies on the relationship bet- ween digital blood flow and blood pressure should also be carried out among subjects with a very severe stage of VWF.

We thank Mr T Partanen, and Ms P Fahlström of the department of epidemiology and biometry, Institute of Occupational Health, Helsinki, for the help with statistics.

Requests for reprints to: Olli Korhonen, MD Institute of Occupational Health, Haartmaninkatu 1, SF-00290 Helsinki 29.

\section{References}

' Teleky L. Pneumatic tools. Occupational Health 1938;1:1-12.

${ }^{2}$ Pyykkö I. Katsaus tärinän terveydellisiin haittoihin. XXII työterveyspäivät. Helsinki: Institute of Occupational Health, 1975:35-48. (In Finnish.)

${ }^{3}$ Raynaud M. De lasphyxie locale et de la gangrene symmetriques des extremité. Paris: Leclerc, 1862: 47-8.

4 Hellström B, Lange Andersen K. Vibration injuries in Norwegian forest workers. Br J Ind Med 1972;29:255-63.

${ }^{5}$ Pyykkö I. The prevalence and symptoms of traumatic vasopastic disease among lumberjacks in Finland. A field study. Work Environ Health 1974;11:118-31.

${ }^{6}$ Matsumoto K, Itoh N, Kasamatsu T, Iwata H. A study on subjective symptoms based on total operating time of chain saw. Jpn $J$ Ind Health 1977;19:22-8.

' Blair HM, Headington JT, Lynch PJ. Occupational trauma, Raynaud phenomenon, and sclerodactylia. Arch Environ Health 1974;28:80-1.

8 Walton KW. The pathology of Raynaud's phenomenon of occupational origin. In: $\mathrm{W}$ Taylor, ed. The vibration syndrome. London-New York: Academic Press, 1974:109-19.

' Agate JN. An outbreak of cases of Raynaud's phenomenon of occupational origin. Br J Ind Med 1949;6:144-63.

${ }^{10}$ Hamilton S. Bulletin of US Department of Labor. No 236, Bureau of Labor Statistics. 1918. Cited by Agate JN'

"Hamilton A. A vasomotor disturbance in the finger of stonecutters. Archiv für Gewerbepathologie und Gewerbehygiene 1930;1:348-58.

${ }_{12}$ Gurdjian ES, Walker LW. Traumatic vasospastic disease of the hand (white fingers). JAMA 1945;129:668-72.

${ }^{13}$ Kumlin T, Wiikeri M, Sumari P. Radiological changes in carpal and metacarpal bones and phalanges caused by chain saw vibration. Br J Ind Med 1973;30:71-3.

${ }^{14}$ Taylor $\mathrm{W}$. The vibration syndrome: introduction. In: W Taylor ed. The vibration syndrome. London: Academic Press, 1974;1-12.

is Pyykkö I, Hyvärinen J. The physiological basis of the traumatic vasospastic disease: a sympathetic vasoconstrictor reflex triggered by high frequency vibration? Work Environ Health 1973;10:36-47.

${ }^{16}$ Hyvärinen J, Pyykkö I, Sundberg S. Vibration in frequencies and amplitudes in the aetiology of traumatic vasopastic disease. Lancet 1973;i:791-4.

${ }^{17}$ Matoba T, Mizobuchi H, Ito T, Chiba M, Toshima H. Further observations of the digital plethysmography in response to auditory stimuli and its clinical applications. Angiology 1981;32:62-72.

${ }^{18}$ Klimkovà-Deutschovà E. Neurologische Aspekte der Vibrationskranheit. Archiv fur Gewerbepathologie und Gewerbehygiene 1966;22:297-305. 
${ }^{19}$ Nalca IF. Vascular disorders and their pathogenesis in connection with vibration disease. Sov Med 1971;34:11-4. (English abstract.)

${ }^{20}$ Olsen N, Nielsen S. Diagnosis of Raynaud's phenomenon in quarrymen's traumatic vasospastic disease. Scand J Work Environ Health 1979;5:249-56.

21 Juul C, Nielsen SL. Locally induced digital vasospasm detected by delayed rewarming in Raynaud's phenomenon of occupational origin. Br J Ind Med 1981;38:87-90.

22 Folkow T, Halbäck M, Weiss L. Cardiovascular responses to acute mental "stress" in spontaneously hypertensive rats (SHR). Acta Physiol Scand 1972;84:7-8A.

${ }^{23}$ Hallbäck M, Folkow B. Cardiovascular responses to acute mental "stress" in spontaneously hypertensive rats. Acta Physiol Scand 1974;90:684-98.

${ }^{24}$ Ashe W, Cook WT, Old JW. Raynaud's phenomenon of occupational origin. Arch Environ Health 1962;5:333-43.

${ }^{25}$ Roddie IC, Shephard IT. Evidence for critical closure of digital resistance vessels with reduced transmural pressure and passive dilatation with increased venous pressure. J Physiol 1957;136:279-87.

${ }^{26}$ Azuma T, Ohhashi T, Sakaguchi M. Vibration-induced hyperresponsiveness of arterial smooth muscle to noradrenaline with special reference to Raynaud's phenomenon in vibration disease. Cardiovasc Res 1978;12:758-64.

${ }^{27}$ Azuma T, Ohhashi T, Sakaguchi M. An approach to the pathogenesis of "white finger" induced by vibratory stimulation: acute but sustained changes in vascular responsiveness of canine hindlimb to noradrenaline. Cardiovasc Res 1980;14:725-30.

${ }^{28}$ Lewis T. Vascular disorders of the limbs. London: MacMillan, 1949.

${ }^{29}$ Pyykkö I, Sairanen E, Korhonen O, Färkkilä M, Hyvärinen J. A decrease in the prevalence and severity of vibration-induced white fingers among lumberjacks in Finland. Scand $J$ Work Environ Health 1978;4:246-54.
${ }^{30}$ Pyykkö I, Korhonen O, Färkkilä M, Starck J, Aatola S. A longitudinal study of vibration syndrome among Finnish forest workers. In: A Brammer, ed. Vibration effects on the hand and arm in industry. New York: John Wiley \& Sons (in press).

${ }^{31}$ Lassen NA, Tönnesen KH, Holstein P. Distal blood pressure. Scand J Clin Lab Invest 1976;36:705-9.

${ }^{32}$ Hirai M, Nielsen SL, Lassen NA. Blood pressure measurement of all five fingers by strain gauge plethysmography. Scand $J$ Clin Lab Invest 1976;36:627-32.

${ }^{33}$ Krähenbühl B, Nielsen SL, Lassen NA. Closure of digital arteries in high vascular tone states as demonstrated by measurement of systolic blood pressure in the finger. Scand J Clin Lab Invest 1977;37:71-6.

${ }^{34}$ Nielsen SL, Lassen NA. Measurement of digital blood pressure after local cooling. J Appl Physiol 1977;43:907-10.

${ }^{35}$ Abrahams DI. Circulation in the extremities. New York: Academic Press, 1967.

${ }^{36}$ Coffman ID, Cohen AS. Total and capillary fingertip blood flow in Raynaud's phenomenon. $N$ Engl J Med 1971;285:259-63.

${ }^{37}$ Folkow B, Hallbäck M, Lundgren Y, Weiss L. Background of increased flow resistance and vascular reactivity in spontaneously hypertensive rats. Acta Physiol Scand 1970;80:93-106.

${ }^{38}$ Magos L, Okos G. Cold dilatation and Raynaud's phenomenon. Arch Environ Health 1963;7:341-5.

${ }^{39}$ Hellström B, Langer AK. Vibration injuries in Norwegian forest workers. Br J Ind Med 1971;8:1-19.

${ }^{40}$ Okada A, Yamashita T, Nagano C, Ikeda T, Yachi A, Shibata S. Studies on the diagnosis and pathogenesis of Raynaud's phenomenon of occupational origin. $\mathrm{Br} J$ Ind Med 1971;28:353-7.

${ }^{41}$ Johansson B, Ljung B, Malmfors T, Olson L. Prejunctional supersensitivity in the rat portal vein as related to its pattern of innervation. Acta Physiol Scand 1970; suppl: 349. 